\title{
Adult neurogenesis in brain repair: cellular plasticity vs. cellular replacement
}

\author{
Giorgia Quadrato $^{1 *}$, Mohamed Y. Elnaggar ${ }^{1,2}$ and Simone Di Giovanni ${ }^{1,3}$ \\ ' Laboratory for NeuroRegeneration and Repair, Center for Neurology, Hertie Institute for Clinical Brain Research, University of Tuebingen, Tuebingen, Germany \\ ${ }^{2}$ Graduate School for Cellular and Molecular Neuroscience, University of Tuebingen, Tuebingen, Germany \\ ${ }^{3}$ Molecular Neuroregeneration, Division of Brain Sciences, Department of Medicine, Imperial College London, London, UK \\ *Correspondence: giorgia.quadrato@uni-tuebingen.de
}

Edited by:

Luca Bonfanti, University of Turin, Italy

Reviewed by:

Ann Turnley, The University of Melbourne, Australia

Keywords: adult neurogenesis, plasticity, brain repair, brain reorganization, connectomics, newborn neurons, survival

\section{INTRODUCTION}

The last decade has seen an exponential increase in research directed to the field of regenerative medicine aimed at using stem cells in the repair of damaged organs including the brain. The therapeutic use of stem cells for neurological disorders includes either the modulation of endogenous stem cells resident in the brain or the introduction of exogenous stem cells into the brain. The final goal of these attempts is to replace damaged dysfunctional cells with new functional neurons. Nevertheless, there are multiple concerns regarding the therapeutic efficacy of the cellular replacement approach both from endogenous and exogenous sources. Indeed the extensive heterogeneity of neuronal subtypes in the brain makes it difficult to drive stem cells to differentiate to specific neuronal subtypes (Hawrylycz et al., 2012), which is a major requirement for regaining the lost neurological function. Furthermore, the fact that the brain is a very complex 3D structure with highly complex hierarchically organized connections raises a question on whether new neurons formed outside the brain niche can be functionally integrated into the preexisting circuitry. An alternative approach to cellular replacement can be enhancing plasticity in newborn neurons in the neurogenic niche to take over a function of a remote brain region. This strategy may have a yet unknown potential as it overcomes the limitations of the cellular replacement approach. In this opinion paper, we discuss limitations and potential of cellular replacement and cellular plasticity in the context of brain repair with a special focus on remote plasticity.

\section{CELLULAR REPLACEMENT FOLLOWING NEUROLOGICAL DISORDERS}

Cellular replacement upon brain damage involves two main strategies: (i) pharmacological or genetic modulation of endogenous neural stem cells (NSCs) and (ii) transplantation of exogenous stem cells.

NSCs resident in the adult brain are characterized by the ability to self-renew their own pool through cell proliferation and by the potential to differentiate into the three main cell types of Central nervous system (CNS): neurons, astrocytes, and oligodendrocytes (Gage, 2000).

Active neurogenesis occurs throughout adulthood in primates and various mammals including; rodents, rabbits, monkeys, and humans (Ming and Song, 2005; Martino et al., 2011). New functional neurons are produced under physiological conditions in two neurogenic niches: the subventricular zone (SVZ) in the lateral wall of the lateral ventricles and the subgranular zone (SGZ) of the dentate gyrus (DG) in the hippocampus (Gage, 2000). Moreover, various studies have shown the presence of "local" progenitors residing in various brain regions outside the stem cell niches including; neocortex, cerebellum, striatum, amygdala, substantia nigra, and hypothalamus (Ming and Song, 2005; Martino et al., 2011; Crociara et al., 2013).

Endogenous cellular replacement requires either: (i) increase in the number of newborn neurons in the neurogenic niches as compared to physiological conditions, (ii) migration of new neurons from the neurogenic niches to the damaged area, or (iii) production of the new neurons from local progenitor cells in the vicinity of the damaged brain. Indeed, various reports have demonstrated the occurrence of these three phenomenona following brain damage. Specifically, it has been shown that neurogenesis can be upregulated in neurogenic niches in response to different brain insults including ischemia (Jin et al., 2001; Harry, 2008; Osman et al., 2011), seizures (Parent and Lowenstein, 2002; Smith et al., 2005) and traumatic brain injury (Dash et al. 2001; Harry, 2008). Similarly, migration of newly generated neurons to the site of damage has been reported following brain ischemia (Arvidsson et al., 2002; Thored et al., 2007). Furthermore, neurogenesis following brain insults has been also reported in areas outside the neurogenic niches including the cortex, striatum, hippocampus, subcortical white matter, and corticospinal system (Sohur et al., 2006).

Although the reactive increase in neurogenesis that occurs following injury may indicate an attempt of the damaged brain to self-repair, this response fails in promoting functional recovery and in producing adequate amounts of newborn neurons that can survive and integrate.

Therefore increasing the number of functional neural precursor cells by increasing their survival rate, via pharmacological or genetic modulation, could be a promising strategy for brain repair.

The other cellular replacement strategy, following neurological insults, involves the transplantation of stem cells from 
exogenous sources into the damaged brain. The most commonly used stem cells are immortalized human neural stem cell lines, mesenchymal stem cells, embryonic stem cells, neuronal progenitors isolated from rodents or humans, and induced pluripotent stem cells (iPSCs) (Liu et al., 2009; Martino et al., 2011). The therapeutic potential of the transplanted stem cells have been validated in various models of diseases and injuries (Shihabuddin et al., 2000; Pluchino et al., 2003; Cummings et al., 2005; Jin et al., 2005). Although varying degrees of functional recovery have been observed, it does not always correlate with the number of newly integrated neurons resulting from the differentiation of the transplanted stem cells. Indeed there is general agreement that transplanted stem cells play various other roles beside cellular replacement in the diseased/damaged brain including neuroprotection and reduction of the inflammatory response via a bystander effect (Martino and Pluchino, 2006; Martino et al., 2011).

\section{LIMITATION OF THE CELLULAR REPLACEMENT APPROACH}

Stem cells-based cellular replacement from endogenous or exogenous sources has many limitations including those stemming from the heterogeneity of neuronal subtypes and the highly complex structure of the brain. During the development of the nervous system different types of neurons are produced in highly controlled manner both temporally and spatially. This process is conserved in different species and fate determination of neural progenitor cells result in several postmitotic progenies with distinct phenotypes (Cepko et al., 1996). Importantly, the molecular signature and the transcriptional regulation of different neuronal subtypes vary enormously between different anatomical regions in the brain (Hawrylycz et al., 2012) limiting the differentiation of transplanted stem cells into specific brain regions and neuronal subtypes. One way to overcome this limitation is to develop techniques to direct the differentiation of neural progenitor cells to a specific phenotype. This solution is not easily applicable due to the limited potential of adult neural progenitor cells to differentiate to most neuronal subtypes.
Indeed the wide heterogeneity of neuronal subtypes in the central nervous system originates during embryonic development from earlier neural precursors cells.

The functional integration of the newly generated neurons in the existing brain circuits is another major limitation to the cell replacement approach for transplanted cells and for cells produced outside the neurogenic niche. This can be attributed to the fact that the brain is composed of highly entangled set of cells and connections with precise stable spatial organization. The introduction of new neurons in the existing brain structure requires complex processes including: (i) directed migration of the new neurons to the proper site of integration and (ii) directed neurite-growth over long distances, which have not been demonstrated in the adult brain outside the neurogenic niches.

Therefore, the introduction of new neurons directly to the site of damage in the brain either by exogenous or endogenous sources faces major challenges such as differentiation to the correct subtype and integration. This leaves to date the newborn neurons in the neurogenic niches as the only cell type shown to be able to functionally integrate in the adult brain circuitry.

Consequently, one fundamental question is how we can make use of the reactive pool of neural precursor cells residing in the neurogenic niches to take over the function of a remote damaged brain region. In order to address this question it will be important to gain knowledge from the plastic properties of the older brothers of neural stem cells, the postmitotic neurons.

\section{CELLULAR PLASTICITY FOLLOWING NEUROLOGICAL DISORDERS}

Postmitotic neurons exhibit a certain degree of plasticity following brain ischemia and traumatic brain injuries. Indeed, despite the permanent structural damage and cellular loss, functional recovery is observed to a certain extent following brain damage (Chollet et al., 1991; Cao et al., 1998).

Neuroplasticity is defined as the brain's ability to reorganize itself by forming new functional synaptic connections throughout life. Continuous remodeling of neuronal connections and cortical maps in response to our experiences occurs to enable neurons to adapt to new situations (Taupin, 2008). Reorganization of brain networks plays also an important role allowing healthy neurons to compensate for damaged neurons (Sbordone et al., 1995; Cramer and Bastings, 2000; Demeurisse, 2000; Weidner et al., 2001). For instance, this functional compensation is evident following brain injury in the hemisphere contralateral to the lesion site. The contralateral hemisphere is reorganized and new connections are formed between intact neurons to take over some of the functions of the injured hemisphere (Takatsuru et al., 2009, 2011). Recent advances in functional imaging, e.g., positron emission tomographic and functional magnetic resonance imaging have indeed confirmed the occurrence of this reorganization (Calautti and Baron, 2003; Butefisch et al., 2006; Crosson et al., 2007; Ward, 2007). There is also clinical evidence that reorganization of the somatosensory cortex contralateral to the lesion site in stroke patients plays important role in the compensation of impaired functions (Chollet et al., 1991; Cao et al., 1998). Furthermore reorganization of brain networks has been reported in patients suffering from aphasia (speechlessness) in which the nondominant right-hemisphere takes over the function of Wernicke's area (speech center normally present in the dominant left hemisphere) (Weiller et al., 1995).

Despite the consistent reports confirming circuitry reorganization in the brain following injury, the molecular and electrophysiological mechanisms controlling this fascinating phenomenon remain still elusive.

Another unexplored aspect of compensatory plasticity includes the question of whether newborn neurons are involved in the reorganization of brain circuitry that occurs following brain injury. However, because of their peculiar cellular and plastic properties, we believe that newborn neurons in the neurogenic niches are important players in this phenomenon.

Indeed it has been shown that newly generated neurons, as compared to mature granule cells, exhibit a lower threshold for induction of LTP (Schmidt-Hieber et al., 2004). This property, facilitating synaptic plasticity, makes young neurons ideally 
suited to adapt to the reorganization of brain networks and to take over a function that is normally played by other brain regions.

Importantly, following brain ischemia, newborn neurons react with a plastic response enhancing not only their proliferation rate but also exhibiting increased spine density and dendritic complexity as compared to resident hippocampal neurons (Liu et al., 1998; Niv et al., 2012).

So far it has not been investigated whether this plastic response includes changes in the pattern of brain connectivity of newborn neurons. However the recent application of retrograde monosynaptic tracing to study the connectome of the newly generated neurons (Deshpande et al., 2013) in neurogenic niches provides us with tools to address this important question.

The next step following the demonstration of the involvement of newborn neurons in brain reorganization would be to increase their plastic potential by increasing their number. This may be achieved, taking advantage of the increase in the proliferation rate of NPCs that normally occurs upon brain damage (Liu et al., 1998), by increasing their integration and survival rate.

Previous work has described a number of intrinsic and extrinsic factors required for newborn neurons survival (see Table 1). The modulation of such factors, important to regulate the survival and integration of newborn neurons in physiological condition, may become even more crucial following brain damage. Recently, cytoskeleton regulators such as Rho kinase and Rho-GTPases have been included among the most important intrinsic regulators of the adult neurogenesis (Christie et al., 2013; Vadodaria and Jessberger, 2013; Vadodaria et al., 2013). Interestingly, the modulation of the RhoPathway is also critical for growth cone collapse, neurite outgrowth and regeneration after neurotrauma in the CNS (McKerracher et al., 2012), making it an ideal target to enhance both cellular plasticity and survival. In this perspective the identification of molecular mechanisms that can be targeted to increase both the number and the plasticity of newborn neurons can increase the probability of functional reorganization of brain networks following injury.

\section{CONCLUSIONS}

The vast amount of information that have been gathered in the recent years about the use of neural stem cells in brain repair indicates that cellular replacement alone cannot lead to effective restoration of function due to the complex anatomical, histological, and functional organization of the brain.

In this perspective, due to their plastic potential and their innate ability to

Table 1 | Factors required for newborn neurons survival and integration in physiological conditions.

\begin{tabular}{|c|c|c|c|}
\hline & Type & Niche & References \\
\hline \multicolumn{4}{|c|}{ EXTRACELLULAR FACTORS } \\
\hline BDNF & Neurotrophin & DG & $\begin{array}{l}\text { Sairanen et al., 2005; } \\
\text { Bergami et al., 2008; } \\
\text { Waterhouse et al., } 2012\end{array}$ \\
\hline GABA & Neurotransmitter & DG & Ge et al., 2006 \\
\hline Glutamate & Neurotransmitter & SVZ & Platel et al., 2010 \\
\hline WNT & Morphogen & DG & $\begin{array}{l}\text { Lie et al., 2005; } \\
\text { Kuwabara et al., } 2009\end{array}$ \\
\hline \multicolumn{4}{|c|}{ INTRACELLULAR FACTORS } \\
\hline NFATc4 & Transcription factor & DG & Quadrato et al., 2012 \\
\hline NF-KappaB p50 & Transcription factor & DG & Denis-Donini et al., 2008 \\
\hline CREB & Transcription factor & DG & Jagasia et al., 2009 \\
\hline Neuro D1 & Transcription factor & DG, SVZ & Gao et al., 2009 \\
\hline PROX1 & Transcription factor & DG & $\begin{array}{l}\text { Lavado et al., 2010; } \\
\text { Karalay et al., } 2011\end{array}$ \\
\hline ROCK (inhibition) & Kinase & DG, SVZ & $\begin{array}{l}\text { Leong et al., 2011; } \\
\text { Christie et al., } 2013\end{array}$ \\
\hline
\end{tabular}

functionally integrate in brain circuits, newborn neurons produced inside the neurogenic niches are the most suitable targets for brain repair. Moreover, the importance of neurogenesis-related plasticity is further supported by the finding that hippocampal neurogenesis occurs in humans throughout adulthood with a modest decline during aging (Spalding et al., 2013). Indeed, the central location of the hippocampus in the medial temporal lobe in the human brain (Haines, 2004) may allow the communication of newborn neurons to various brain circuits.

In this scenario strategies that enhance the survival and the plasticity of newly generated neurons in the dentate gyrus may be the most effective to foster the functional reorganization of brain circuits following injury.

\section{ACKNOWLEDGMENTS}

We thank the Hertie Foundation and the DFG (to Simone Di Giovanni) and the Fortüne Program of the University of Tübingen (to Giorgia Quadrato) for financial support. We apologize to authors whose original papers could not be cited due to space constraints.

\section{REFERENCES}

Arvidsson, A., Collin, T., Kirik, D., Kokaia, Z., and Lindvall, O. (2002). Neuronal replacement from endogenous precursors in the adult brain after stroke. Nat. Med. 8, 963-970. doi: 10.1038/nm747

Bergami, M., Rimondini, R., Santi, S., Blum, R., Gotz, M., and Canossa, M. (2008). Deletion of TrkB in adult progenitors alters newborn neuron integration into hippocampal circuits and increases anxiety-like behavior. Proc. Natl. Acad. Sci. U.S.A. 105, 15570-15575. doi: 10.1073/pnas.0803702105

Butefisch, C. M., Kleiser, R., and Seitz, R. J. (2006). Post-lesional cerebral reorganisation: evidence from functional neuroimaging and transcranial magnetic stimulation. J. Physiol. Paris 99, 437-454. doi: 10.1016/j.jphysparis.2006.03.001

Calautti, C., and Baron, J. C. (2003). Functional neuroimaging studies of motor recovery after stroke in adults: a review. Stroke 34, 1553-1566. doi: 10.1161/01.STR.0000071761.36075.A6

Cao, Y., D’Olhaberriague, L., Vikingstad, E. M., Levine, S. R., and Welch, K. M. (1998). Pilot study of functional MRI. to assess cerebral activation of motor function after poststroke hemiparesis. Stroke 29, 112-122. doi: 10.1161/01.STR.29.1.112

Cepko, C. L., Austin, C. P., Yang, X., Alexiades, M., and Ezzeddine, D. (1996). Cell fate determination in the vertebrate retina. Proc. Natl. Acad. Sci. U.S.A. 93, 589-595. doi: 10.1073/pnas.93.2.589

Chollet, F., DiPiero, V., Wise, R. J., Brooks, D. J., Dolan, R. J., and Frackowiak, R. S. (1991) The functional anatomy of motor recovery after 
stroke in humans: a study with positron emission tomography. Ann. Neurol. 29, 63-71. doi: 10.1002/ana.410290112

Christie, K. J., Turbic, A., and Turnley, A. M. (2013). Adult hippocampal neurogenesis, Rho kinase inhibition and enhancement of neuronal survival. Neuroscience 247, 75-83. doi: 10.1016/j.neuroscience.2013.05.019

Cramer, S. C., and Bastings, E. P. (2000). Mapping clinically relevant plasticity after stroke. Neuropharmacology 39, 842-851. doi: 10.1016/S0028-3908(99)00258-0

Crociara, P., Parolisi, R., Conte, D., Fumagalli, M., and Bonfanti, L. (2013). Cellular and molecular characterization of multipolar Map5-expressing cells: a subset of newly generated, stage-specific parenchymal cells in the mammalian central nervous system. PLoS ONE 8:e63258. doi: 10.1371/journal.pone.0063258

Crosson, B., McGregor, K., Gopinath, K. S., Conway, T. W., Benjamin, M., Chang, Y. L., et al. (2007). Functional MRI. of language in aphasia: a review of the literature and the methodological challenges. Neuropsychol. Rev. 17, 157-177. doi: 10.1007/s11065-007-9024-Z

Cummings, B. J., Uchida, N., Tamaki, S. J., Salazar, D. L., Hooshmand, M., Summers, R., et al. (2005). Human neural stem cells differentiate and promote locomotor recovery in spinal cordinjured mice. Proc. Natl. Acad. Sci. U.S.A. 102, 14069-14074. doi: 10.1073/pnas.0507063102

Dash, P. K., Mach, S. A., and Moore, A. N. (2001). Enhanced neurogenesis in the rodent hippocampus following traumatic brain injury. J. Neurosci. Res. 63, 313-319. doi: 10.1002/1097-4547(20010215)63:4\%3C313::AIDJNR1025\%3E3.3.CO;2-W

Demeurisse, G. (2000). Mechanisms of functional restoration after brain injury. Acta Neurol. Belg. 100, 77-83.

Denis-Donini, S., Dellarole, A., Crociara, P., Francese, M. T., Bortolotto, V., Quadrato, G., et al. (2008). Impaired adult neurogenesis associated with short-term memory defects in NF-kappaB p50-deficient mice. J. Neurosci. 28, 3911-3919. doi: 10.1523/JNEUROSCI.0148-08.2008

Deshpande, A., Bergami, M., Ghanem, A., Conzelmann, K. K., Lepier, A., Gotz, M., et al. (2013). Retrograde monosynaptic tracing reveals the temporal evolution of inputs onto new neurons in the adult dentate gyrus and olfactory bulb. Proc. Natl. Acad. Sci. U.S.A. 110, E1152-E1161. doi: $10.1073 /$ pnas. 1218991110

Gage, F. H. (2000). Mammalian neural stem cells. Science 287, 1433-1438. doi: 10.1126/science.287.5457.1433

Gao, Z., Ure, K., Ables, J. L., Lagace, D. C., Nave, K. A., Goebbels, S., et al. (2009). Neurodl is essential for the survival and maturation of adultborn neurons. Nat. Neurosci. 12, 1090-1092. doi: 10.1038/nn.2385

Ge, S., Goh, E. L., Sailor, K. A., Kitabatake, Y., Ming, G. L., and Song, H. (2006). GABA regulates synaptic integration of newly generated neurons in the adult brain. Nature 439, 589-593. doi: 10.1038 /nature 04404

Haines, D. E. (2004). Neuroanatomy: An Atlas of Structures, Sections, and Systems. Baltimore, MD: Lippincott Williams and Wilkins.
Harry, G. J. (2008). "Neurogenesis and brain repair," in Neuroimmune Pharmacology. eds H. Gendelman and T. Ikezu (New York, NY: Springer), 445-462. doi: 10.1007/978-0-387-72573-4_32

Hawrylycz, M. J., Lein, E. S., Guillozet-Bongaarts, A. L., Shen, E. H., Ng, L., Miller, J. A., et al.( 2012). An anatomically comprehensive atlas of the adult human brain transcriptome. Nature 489, 391-399. doi: 10.1038/nature11405

Jagasia, R., Steib, K., Englberger, E., Herold, S., FausKessler, T., Saxe, M., et al. (2009). GABA-cAMP response element-binding protein signaling regulates maturation and survival of newly generated neurons in the adult hippocampus. J. Neurosci. 29, 7966-7977. doi: 10.1523/JNEUROSCI.105409.2009

Jin, K., Minami, M., Lan, J. Q., Mao, X. O., Batteur, S., Simon, R. P., et al. (2001). Neurogenesis in dentate subgranular zone and rostral subventricular zone after focal cerebral ischemia in the rat. Proc. Natl. Acad. Sci. U.S.A. 98, 4710-4715. doi: 10.1073/pnas.081011098

Jin, K., Sun, Y., Xie, L., Mao, X. O., Childs, J., Peel, A., et al. (2005). Comparison of ischemia-directed migration of neural precursor cells after intrastriatal, intraventricular, or intravenous transplantation in the rat. Neurobiol. Dis. 18, 366-374. doi: 10.1016/j.nbd.2004.10.010

Karalay, O., Doberauer, K., Vadodaria, K. C., Knobloch, M., Berti, L., Miquelajauregui, A., et al. (2011). Prospero-related homeobox 1 gene (Prox1) is regulated by canonical Wnt signaling and has a stage-specific role in adult hippocampal neurogenesis. Proc. Natl. Acad. Sci. U.S.A. 108, 5807-5812. doi: 10.1073/pnas. 1013456108

Kuwabara, T., Hsieh, J., Muotri, A., Yeo, G., Warashina, M., Lie, D. C., et al. (2009). Wntmediated activation of NeuroDl and retroelements during adult neurogenesis. Nat. Neurosci. 12, 1097-1105. doi: 10.1038/nn.2360

Lavado, A., Lagutin, O. V., Chow, L. M., Baker, S. J., and Oliver, G. (2010). Proxl is required for granule cell maturation and intermediate progenitor maintenance during brain neurogenesis. PLoS Biol. 8:e1000460. doi: 10.1371/journal.pbio. 1000460

Leong, S. Y., Faux, C. H., Turbic, A., Dixon, K. J., and Turnley, A. M. (2011). The Rho kinase pathway regulates mouse adult neural precursor cell migration. Stem Cells 29, 332-343. doi: 10.1002/ stem. 577

Lie, D. C., Colamarino, S. A., Song, H. J., Desire, L., Mira, H., Consiglio, A., et al. (2005). Wnt signalling regulates adult hippocampal neurogenesis. Nature 437, 1370-1375. doi: 10.1038/ nature 04108

Liu, J., Solway, K., Messing, R. O., and Sharp, F. R. (1998). Increased neurogenesis in the dentate gyrus after transient global ischemia in gerbils. J. Neurosci. 18, 7768-7778.

Liu, Y. P., Lang, B. T., Baskaya, M. K., Dempsey, R. J., and Vemuganti, R. (2009). The potential of neural stem cells to repair stroke-induced brain damage. Acta Neuropathol. 117, 469-480. doi: 10.1007/s00401-009-0516-1

Martino, G., and Pluchino, S. (2006). The therapeutic potential of neural stem cells. Nat. Rev. Neurosci. 7, 395-406. doi: 10.1038/nrn1908
Martino, G., Pluchino, S., Bonfanti, L., and Schwartz, M. (2011). Brain regeneration in physiology and pathology: the immune signature driving therapeutic plasticity of neural stem cells. Physiol. Rev. 91, 1281-1304. doi: 10.1152/physrev.00032.2010

McKerracher, L., Ferraro, G. B., and Fournier, A. E. (2012). Rho signaling and axon regeneration. Int Rev. Neurobiol. 105, 117-140. doi: 10.1016/B9780-12-398309-1.00007-X

Ming, G. L., and Song, H. (2005). Adult neurogenesis in the mammalian central nervous system. Annu. Rev. Neurosci. 28, 223-250. doi: 10.1146/annurev.neuro.28.051804.101459

Niv, F., Keiner, S., Krishna, -K., Witte, O. W., Lie, D. C., and Redecker, C. (2012). Aberrant neurogenesis after stroke: a retroviral cell labeling study. Stroke 43, 2468-2475. doi: 10.1161/STROKEAHA.112.660977

Osman, A. M., Porritt, M. J., Nilsson, M., and Kuhn, H. G. (2011). Long-term stimulation of neural progenitor cell migration after cortical ischemia in mice. Stroke 42, 3559-3565. doi: 10.1161/STROKEAHA.111.627802

Parent, J. M., and Lowenstein, D. H. (2002). Seizureinduced neurogenesis: are more new neurons good for an adult brain? Prog. Brain Res. 135, 121-131. doi: 10.1016/S0079-6123(02)35012-X

Platel, J. C., Dave, K. A., Gordon, V., Lacar, B., Rubio, M. E., and Bordey, A. (2010). NMDA receptors activated by subventricular zone astrocytic glutamate are critical for neuroblast survival prior to entering a synaptic network. Neuron $65,859-872$. doi: 10.1016/j.neuron.2010.03.009

Pluchino, S., Quattrini, A., Brambilla, E., Gritti, A., Salani, G., Dina, G., et al. (2003). Injection of adult neurospheres induces recovery in a chronic model of multiple sclerosis. Nature 422, 688-694. doi: 10.1038 /nature01552

Quadrato, G., Benevento, M., Alber, S., Jacob, C., Floriddia, E. M., Nguyen, T., et al. (2012). Nuclear factor of activated T cells (NFATc4) is required for BDNF-dependent survival of adult-born neurons and spatial memory formation in the hippocampus. Proc. Natl. Acad. Sci. U.S.A. 109 E1499-E1508. doi: 10.1073/pnas.1202068109

Sairanen, M., Lucas, G., Ernfors, P., Castren, M., and Castren, E. (2005). Brain-derived neurotrophic factor and antidepressant drugs have different but coordinated effects on neuronal turnover, proliferation, and survival in the adult dentate gyrus. J. Neurosci. 25, 1089-1094. doi: 10.1523/JNEUROSCI.3741-04.2005

Sbordone, R. J., Liter, J. C., and Pettler-Jennings, P. (1995). Recovery of function following severe traumatic brain injury: a retrospective 10-year follow-up. Brain Inj. 9, 285-299. doi: 10.3109/02699059509008199

Schmidt-Hieber, C., Jonas, P., and Bischofberger, J. (2004). Enhanced synaptic plasticity in newly generated granule cells of the adult hippocampus. Nature 429, 184-187. doi: 10.1038/nature02553

Shihabuddin, L. S., Horner, P. J., Ray, J., and Gage, F. H. (2000). Adult spinal cord stem cells generate neurons after transplantation in the adult dentate gyrus. J. Neurosci. 20, 8727-8735.

Smith, P. D., McLean, K. J., Murphy, M. A., Turnley, A. M., and Cook, M. J. (2005). Seizures, not hippocampal neuronal death, provoke neurogenesis in a mouse rapid electrical amygdala kindling 
model of seizures. Neuroscience 136, 405-415. doi: 10.1016/j.neuroscience.2005.07.055

Sohur, U. S., Emsley, J. G., Mitchell, B. D., and Macklis, J. D. (2006). Adult neurogenesis and cellular brain repair with neural progenitors, precursors and stem cells. Philos. Trans. R. Soc. Lond. B Biol. Sci. 361, 1477-1497. doi: 10.1098/rstb.2006.1887

Spalding, K. L., Bergmann, O., Alkass, K., Bernard, S., Salehpour, M., Huttner, H. B., et al. (2013). Dynamics of hippocampal neurogenesis in adult humans. Cell 153, 1219-1227. doi: 10.1016/j.cell.2013.05.002

Takatsuru, Y., Fukumoto, D., Yoshitomo, M., Nemoto, T., Tsukada, H., and Nabekura, J. (2009). Neuronal circuit remodeling in the contralateral cortical hemisphere during functional recovery from cerebral infarction. J. Neurosci. 29, 10081-10086. doi: 10.1523/JNEUROSCI.1638-09.2009

Takatsuru, Y., Koibuchi, N., and Nabekura, J. (2011). Unilateral infarction of the visual cortex (VC) induced an increase in dendritic spine turnover in contralateral VC. Neurosci. Lett. 488, 97-100. doi: 10.1016/j.neulet.2010.11.010

Taupin, P. (2008). Stem Cells and Regenerative Medicine: Volume I: Adult Neurogenesis and Neural Stem Cells. New York, NY: Nova Science Publishers.

Thored, P., Wood, J., Arvidsson, A., Cammenga, J., Kokaia, Z., and Lindvall, O. (2007). Long- term neuroblast migration along blood vessels in an area with transient angiogenesis and increased vascularization after stroke. Stroke 38, 3032-3039. doi: 10.1161/STROKEAHA. 107.488445

Vadodaria, K. C., Brakebusch, C., Suter, U., and Jessberger, S. (2013). Stage-specific functions of the small Rho GTPases Cdc42 and Racl for adult hippocampal neurogenesis. J. Neurosci. 33, 1179-1189. doi: 10.1523/JNEUROSCI.210312.2013

Vadodaria, K. C., and Jessberger, S. (2013). Maturation and integration of adult born hippocampal neurons: signal convergence onto small Rho GTPases. Front. Synaptic Neurosci. 5:4. doi: 10.3389/fnsyn.2013.00004

Ward, N. S. (2007). Future perspectives in functional neuroimaging in stroke recovery. Eura. Medicophys. 43, 285-294.

Waterhouse, E. G., An, J. J., Orefice, L. L., Baydyuk, M., Liao, G. Y., Zheng, K., et al. (2012). BDNF promotes differentiation and maturation of adult-born neurons through GABAergic transmission. J. Neurosci. 32, 14318-14330. doi: 10.1523/JNEUROSCI.0709-12.2012

Weidner, N., Ner, A., Salimi, N., and Tuszynski, M. H. (2001). Spontaneous corticospinal axonal plasticity and functional recovery after adult cen- tral nervous system injury. Proc. Natl. Acad. Sci. U.S.A. 98, 3513-3518. doi: 10.1073/pnas. 051626798

Weiller, C., Isensee, C., Rijntjes, M., Huber, W., Muller, S., Bier, D., et al. (1995). Recovery from Wernicke's aphasia: a positron emission tomographic study. Ann. Neurol. 37, 723-732. doi: 10.1002/ana.410370605

Received: 15 January 2014; paper pending published: 22 January 2014; accepted: 22 January 2014; published online: 12 February 2014.

Citation: Quadrato G, Elnaggar MY and Di Giovanni S (2014) Adult neurogenesis in brain repair: cellular plasticity vs. cellular replacement. Front. Neurosci. 8:17. doi: 10.3389/fnins.2014.00017

This article was submitted to Neurogenesis, a section of the journal Frontiers in Neuroscience.

Copyright () 2014 Quadrato, Elnaggar and Di Giovanni. This is an open-access article distributed under the terms of the Creative Commons Attribution License (CC BY). The use, distribution or reproduction in other forums is permitted, provided the original author(s) or licensor are credited and that the original publication in this journal is cited, in accordance with accepted academic practice. No use, distribution or reproduction is permitted which does not comply with these terms. 